\title{
Interactive comment on "Dynamics of primary productivity in the northeastern Bay of Bengal over the last 26000 years" by Xinquan Zhou et al.
}

\section{Anonymous Referee \#1}

Received and published: 10 April 2020

\section{General comments:}

Zhou et al - present a new primary productivity (PP) record since the 26 ka from the Bay of Bengal and assess the potential drivers of PP variability during the same period. Hereafter, I provide detailed review of the manuscript by highlighting the main strengths and shortcomings of the manuscript. To briefly summarize, the manuscript requires major revision before publication and section-by-section review of the manuscript are presented following general comments.

\section{Merits:}

PP variability across timescales in the Bay of Bengal is not as very well researched as it is in other oceanographic settings such as the Arabian Sea, where strong summer 
monsoon winds are known to promote upwelling and PP. This study, which presents high-resolution PP proxy data from the Bay of Bengal spanning the last $26 \mathrm{kyrs}$, is therefore a very welcome contribution. The fact that the study integrates model outputs and proxy data to unravel the relationship between PP variability and monsoon intensity is also commendable. The manuscript addresses relevant scientific questions within the scope of CP and to my knowledge, provides the first record of its kind from the Bay of Bengal. The manuscript meets several of CP peer review guidelines/criteria:

1. Does the paper address relevant scientific questions within the scope of CP? Yes. 2. Does the paper present novel concepts, ideas, tools, or data? Yes. 3. Are the scientific methods and assumptions valid and clearly outlined? Yes. 4. Is the description of experiments and calculations sufficiently complete and precise to allow their reproduction by fellow scientists (traceability of results)? Yes. 5. Do the authors give proper credit to related work and clearly indicate their own new/original contribution? Yes. 6. Does the title clearly reflect the contents of the paper? Yes. 7. Does the abstract provide a concise and complete summary? Yes. 8. Are mathematical formulae, symbols, abbreviations, and units correctly defined and used? Yes. 9. Are the number and quality of references appropriate? Yes (few references are suggested).

\section{Critique:}

The overall structure of the manuscript and occasional lack of clarity in some sections is a major shortcoming of the manuscript. For example, results from the model outputs are not fully integrated with proxy data and are rather independently summarized. Although, this manuscript presents an important dataset, which is of interest for the scientific community, some of the interpretations need to be significantly refined and I find few of them not convincing at all (see my comments on the discussion section below). The fact that only figures are provided as the supplementary information is also unhelpful and I believe a short text summary is warranted. To summarize, the manuscript in its present form does not meet the following CP peer review guidelines/criteria: 
1. Are substantial conclusions reached? Needs to be improved (see detailed comments below). 2. Are the results sufficient to support the interpretations and conclusions? In general yes but some of the interpretations need to be improved 3 . Is the overall presentation well structured and clear? Needs to be improved. 4. Is the language fluent and precise? In general yes but there is occasional lack of clarity in some sections. 5. Should any parts of the paper (text, formulae, figures, tables) be clarified, reduced, combined, or eliminated? Some discussion sections can be combined to improve clarity and train of thought. 6 . Is the amount and quality of supplementary material appropriate? The supplementary information lack sufficient information and needs to be significantly improved.

Detailed reviews (section-by-section) 1) Introduction

The introduction section of the manuscript provides sufficient literature review and is quite clear in identifying the key knowledge gaps in the literature. Overall, the introduction section is generally admissible but few descriptions need to be refined. The introduction section establishes originality and the comments provided hereafter are, therefore, mostly typographical, intended to improve overall clarity of the Introduction section.

Line 30: The way the monsoon is currently defined need to be improved.

Here, the monsoon is practically presented as a giant sea breeze that is responsive to changes in the land-sea thermal contrast alone and excludes the more complex aspects of the monsoon and its relation with the tropical ocean on seasonal to interannual to decadal timescales (e.g. ENSO and IOD).

Line 40-53: The subsequent section provides a detailed summary of the oceanographic setting in the Bay of Bengal and Andaman Sea. To be more articulate and improve clarity, it's probably best that comparisons within the Arabian Sea and differences with in the broader Northern Indian Ocean oceanography are presented in the introduction section. 
2) Site description and oceanographic setting

This section provides a detailed summary of the oceanographic setting of the studied site and is well written.

Are there any notable differences in seasonal PP variability between the Bay of Bengal and the Andaman Sea? Perhaps a sentence or two addressing the above question will be helpful.

\section{3) Materials and Methods}

This section provides a detailed summary of the methodology and is generally well written. However, information provided on age model reconstruction is insufficient and citation of Figure 2 is not very useful either. I suggest that the authors provide a summary of the age model including changes in the rate of sedimentation etc. This can be included in the same section or in the form of a supplementary material.

\section{4) Results and discussions}

This section of the manuscript is poorly structured and in my opinion, the weakest part of the manuscript. For example, a large chunk of the text (e.g. section 4.3, section 4.3.1: lines $300-317$ ) should have been included in the methodology section. This has made the discussion section overall very descriptive and lacking in substance, and most crucially hard to follow. One way of overcoming this predicament is to divide this section in to two separate sections (i.e., Results and Discussions). For example, the proxy data and model data results can be grouped into two subsections and the discussion section should focus on the dynamics of PP variability over the studied time interval. The Discussion section should also integrate both proxy data and model inferences to build a more coherent understanding of PP variability over the last 26 kyrs.

Looking at the PP record, it is clear that there are three distinct time intervals that can be discussed separately including the highly variable LGM (?), the last deglaciation

\section{CPD}

Interactive comment
Printer-friendly version

Discussion paper 
period marked by an abrupt shift in PP centered around the BA and the Holocene period, which displays a more gradual change. Therefore, dividing the discussion section accordingly and zooming on these three distinct periods will significantly improve clarity.

Lines 205 - 208: the authors write 'at millennial-scale, large magnitude PP oscillations, are observed during the deglaciation (19-11 kyr BP), showing similar features than those found in the Greenland ice core $\delta 180$ record, representing the rapid climatic changes in north hemispheric high-latitude areas (Fig. 2; Stuiver and Grootes, 2000).'

But it is stated in section 3.1 that the age model, although primarily based on 31 AMS $14 \mathrm{C}$ dates, it was still tuned to GISP2 Greenland ice core $\delta 180$ curve. Can this be considered circular reasoning?

Lines 255-229: the authors write, 'Several pieces of evidence suggest that millennialscale variations of PP between 26 and $19 \mathrm{kyr}$ (i.e. before the LGM) chiefly resulted from wind-driven mixing. First, high PP values are reached during intervals of low surface water salinity. If these PP variations (and upper water column stratification) were primarily driven by precipitation - evaporation changes, the opposite relationship would be expected, and PP would peak at periods of higher salinity because of the weaker barrier layer effect'.

Can you independently verify if the wind-driven mixing in the Northern Indian Ocean was enhanced during the LGM? Which are the intervals of low salinity during the LGM? Isn't the LGM Andaman Sea significantly more saline compared to other periods such as the Holocene? How does precipitation minus evaporation impact PP variability in general? What inferences can be made on LGM PP variability from the LGM experiments? These questions, hopefully, will trigger more in-depth discussions on the LGM oceanography and monsoon paleoclimatology and a thorough analysis of the dataset at your disposal (both proxy observations and model outputs).

Printer-friendly version

Lines 247- 251: the authors write, 'The factors controlling PP on the millennial-scale

Interactive

comment 
over the last $19 \mathrm{kyr}$, appear to differ from those acting before the LGM. A strong impact of wind-related changes on vertical stratification is unlikely given that river runoff (Gebregiorgis et al., 2016), together with the precipitation (Dutt et al., 2015; ContrerasRosales et al., 2014), gradually strengthened in this area during the last deglaciation up to the mid-Holocene, due to stronger southwest monsoon circulation (Fig. 4c-g)'.

Although, this is interpretation is well supported, it should also be noted that the PP record during the last deglaciation is also marked by a more abrupt transition. One of the explanations provided involved the collapse of the AMOC and given that stratification changes in the Bay of Bengal/Andaman Sea are driven by changes in monsoon intensity, how does the AMOC (oceanographic processes) impact the monsoon (predominantly atmospheric in nature)? Is the position of the ITCZ the only viable explanation? Note that important clues that will help answer these questions are provided in lines $294-299$ and section 4.3.2. This is why I recommended complete restructuring of the discussion section.

In section 4.1 (line 217): The authors write that, 'PP peaks are related to low SSS intervals before the LGM, and high SSS intervals over the last $19 \mathrm{kyr}$ '.

Although, PP did not significantly change over the course of the Holocene, there appears to be a clear discrepancy between the gradual monsoon intensification over the Holocene and PP variability. PP variability over the course of the last deglaciation and the Holocene are clearly different. Proxy data shown in Figure 2 suggest that estimated $\mathrm{PP}$ has lower valued during the Mid-Holocene ( $90 \mathrm{gC} \mathrm{m}-2 \mathrm{yr}-1)$ compared to late Holocene ( $\sim 130 \mathrm{gC} \mathrm{m}-2 \mathrm{yr}-1)$. This, however, is not discussed in any detail and the way the discussion section is structured is at fault again.

In section 4.1 (lines $204-205$ ): it is briefly mentioned that PP variability shows 'an opposite trend compared to insolation (Fig. $4 \mathrm{a}, \mathrm{h}$ )' and in section 4.3 .1 it is stated that 'insolation is the main climate forcing factor during the Holocene'.

Why do we have the monsoon peaking later during the mid-Holocene lagging maximum 
Northern Hemisphere summer insolation by few kyrs then? The lagged response of the monsoon to insolation forcing suggests that orbital scale monsoon variability is more complex (see Clemens et al., 2003; Caley et al., 2011; Gebregiorgis et al., 2018). Having this in mind, I would therefore encourage the authors to have a more critical outlook on PP variability over the course of the Holocene. I also recommend including Figure S3 - S6 in the main text body and can be used to gain some unique insights on LGM, deglacial and Holocene PP variability. Perhaps Fig. 3 can be moved to the supplementary section.

5) Conclusion

Provides a good summary of the main findings of the paper in its present state and I look forward to reading the revised version of the manuscript. Well done!

Additional comments for the authors

Line 57: What 'fast changes'? Please rephrase.

Line 61: PP record or paleo-PP record. Stick with one for consistency.

Line 61: Da Silva et al., 2017 is a relevant reference here.

Line 62: 'tropical ocean ecology' is very broad and I am not sure this is accurate as well. Perhaps Northern Indian Ocean ecology is more appropriate.

Line 73: ‘High-time-resolution' or 'High-temporal-resolution'? 'High-resolution' is a perhaps a better phrase.

Line 74: Why is it important that the 'studied period covers a complete precession cycle'? This sentences need to be qualified or delete otherwise.

Line 80: 'interpret' is perhaps a better word here than 'analyze'.

Line 199-200: 'At orbital scale' - remove.

Line 202: use 'maximum or minimum Northern Hemisphere $(\mathrm{NH})$ summer insolation' 
instead of low or high insolation with no reference to the latitude or the season.

Line 205: 'On millennial timescale...'

Line 211: 'Synchronous vs. asynchronous' rather than 'Negatively vs. positively correlated' and of course 'correlation' being a statistical term.

Interactive

Line 290-291: Rephrase or remove

'During the Holocene, insolation is the main climate forcing factor since other forcing (i.e. greenhouse gas, ice volume, coastlines, vegetation) are relatively stable after the deglaciation.

Line 291-292: Rephrase. Perhaps, a sentence along these lines will do: 'the response of the Indian monsoon to changes in orbital insolation has previously been examined using both AGCMs and ocean-atmosphere general circulation models...(Refs).)'

'The mechanisms that force monsoon climate to change were studied by many modeling works (Refs).'

Figures S1, S5, S6 are not cited in the main text and please add supplementary text to the supplementary information. Also make sure that the figures are in chronological order.

\section{References}

Caley, T., Malaizé, B., Zaragosi, S., Rossignol, L., Bourget, J., Eynaud, F., Martinez, P., Giraudeau, J., Charlier, K. and Ellouz-Zimmermann, N., 2011. New Arabian Sea records help decipher orbital timing of Indo-Asian monsoon. Earth and Planetary Science Letters, 308(3-4), pp.433-444.

Clemens, S.C. and Prell, W.L., 2003. A 350,000 year summer-monsoon multi-proxy stack from the Owen Ridge, Northern Arabian Sea. Marine Geology, 201(1-3), pp.3551. 
Da Silva, R., Mazumdar, A., Mapder, T., Peketi, A., Joshi, R.K., Shaji, A., Mahalakshmi, P., Sawant, B., Naik, B.G., Carvalho, M.A. and Molletti, S.K., 2017. Salinity stratification controlled productivity variation over 300 ky in the Bay of Bengal. Scientific reports, 7(1), pp.1-7.

Gebregiorgis, D., Hathorne, E.C., Giosan, L., Clemens, S., Nürnberg, D. and Frank, M., 2018. Southern Hemisphere forcing of South Asian monsoon precipitation over the

Interactive past 1 million years. Nature communications, 9(1), pp.1-8.

Interactive comment on Clim. Past Discuss., https://doi.org/10.5194/cp-2020-27, 2020. 